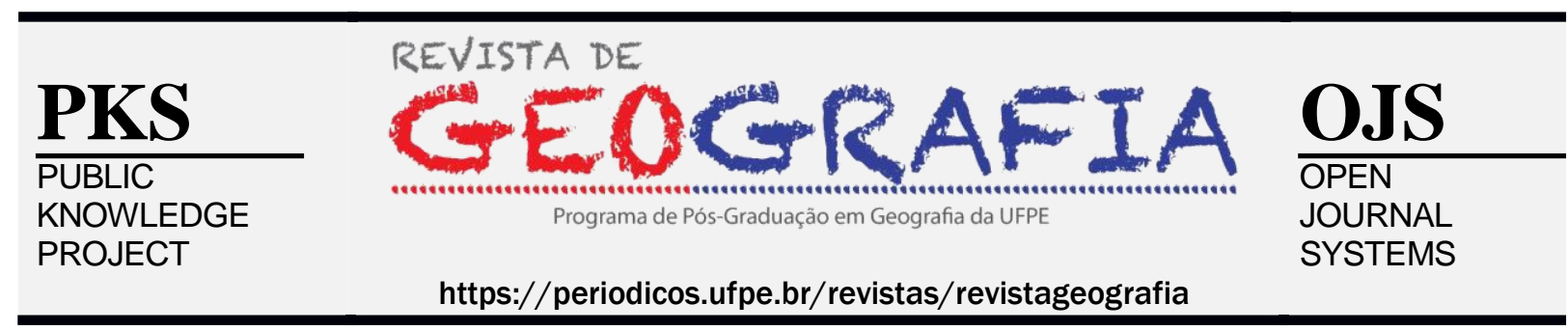

\title{
APRENDIZAGEM COLABORATIVA NA FORMAÇÃO E PRÁTICA DOCENTE EM GEOGRAFIA: DIÁLOGOS, RUPTURAS E CAMINHOS CONTEMPORÂNEOS
}

\author{
Mateus Ferreira Santos ${ }^{1}$, Francisco Kennedy Silva dos Santos ${ }^{2}$, Lucas Antônio Viana \\ Botelho ${ }^{3}$
}

\author{
${ }^{1}$ Universidade Federal de Pernambuco.E-mail: mateusfst@hotmail.com \\ ${ }^{2}$ Universidade Federal de Pernambuco.E-mail: kennedyufpe@gmail.com \\ ${ }^{3}$ Universidade Federal de Pernambuco.E-mail: lucasviana.botelho@gmail.com
}

Artigo recebido em 12/07/2019 e aceito em 26/10/2019

\begin{abstract}
RESUMO
As redes digitais transformaram a sociedade moderna, a percepção do tempo, do espaço e a forma como aprendemos. Além disso, possibilitaram novas formas de saber e construção de conhecimentos, visto que hoje os indivíduos têm a possibilidade de se conectar com o mundo e, de maneira colaborativa, construir e ressignificar conhecimentos que até pouco tempo atrás eram inviáveis. Posto isso, o presente trabalho objetiva apresentar reflexões e aproximações entre o método da aprendizagem colaborativa e a formação e prática docente em Geografia munidos das redes digitais, destacando desafios e possibilidades no enfrentamento de modelos de ensino, tidos como tradicionais, que estão desconexos das realidades que os alunos têm apresentando. $\mathrm{O}$ artigo apoia-se em uma perspectiva crítica, que dá suporte ao aprofundamento de discussões quanto às redes digitais inseridas em contextos pedagógicos. As temáticas aqui adotadas são extremamente significativas, uma vez que não se esgota no contexto escolar, mas estão relacionadas à formação e o contexto social.

Palavras-chave: Redes Digitais; Aprendizado colaborativo; Formação de professor.
\end{abstract}

\section{COLLABORATIVE LEARNING IN FORMATION AND TEACHING PRACTICE IN GEOGRAPHY: DIALOGUES, RUPTURES AND CONTEMPORARY PATHWAYS}

\begin{abstract}
Digital networks have transformed modern society, the perception of time, space and the way we learn. In addition, they enabled new ways of knowing and building knowledge, since today individuals have the possibility to connect with the world and, in a collaborative way, to build and re-signify knowledge that until recently were not feasible. Thus, the present work aims to present reflections and approaches between the collaborative learning method and the teacher training and practice in Geography with digital networks, highlighting challenges and possibilities in the confrontation of traditional teaching models that are disconnected from the realities that Students have presented. The article is based on a critical perspective, which supports the deepening of discussions about digital networks inserted in pedagogical contexts. The themes adopted here are extremely significant, since they are not exhaustive in the school context, but are related to the formation and the social context.
\end{abstract}

Keywords: Digital Networks; Collaborative Learning; Teacher formation 


\section{INTRODUÇÃO}

Educar é e sempre foi um processo cada vez mais complexo para o desenvolvimento das sociedades modernas. Uma das causas que justificam esse fato são as rápidas mudanças societárias globais que têm exigido dos professores a busca por outros mecanismos e formas de ensinar. Muito se tem avançado nesse quesito, porém há ainda desafios, os quais têm contribuído para que o caminho seja visto como tortuoso e perigoso. Inovar é sempre desafiador, pois requer a des-re-construção de pontos de vista e ações já consolidadas nos processos educativos. Atualmente, amplia-se, de forma considerável, a atenção dos profissionais da educação preocupados em entender e dimensionar suas práticas tendo em vista as transformações globais e os aspectos referentes à produção de conhecimentos.

Discutir os processos que condicionam a aprendizagem dos alunos dos diferentes ciclos de ensino tem despertado nos pesquisadores em educação novos olhares quanto à eficácia de metodologias, já que os obsoletos moldes e modelos de práticas - as famosas "receitas de bolo" - adotados por alguns professores não mais atendem às necessidades dos educandos (KENSKI, 2012). Não que elas devam ser extintas, mas o ensino nos dias atuais nos conduz a repensar as diferentes formas de trabalhar conteúdos, relações ampliadas com os alunos e maiores compreensões dos eventos sociais que vêm surgindo.

O uso das Novas Tecnologias Digitais da Informação e Comunicação - NTDIC têm contribuído para o surgimento de inúmeras discussões e problemáticas no cenário escolar, tanto pela má apropriação por parte dos alunos em sala, quanto pelas resistências e dificuldades de professores em seu manuseio (SANTAELLA, 2003; PRETTO, 2011; ALENCAR; MOURA; BITENCOURT, 2013; OSTROVSKI e RAITZ, 2016). Em contrapartida, inúmeras pesquisas e experiências vêm sendo relatadas, apresentando as NTDIC e a escola como parceiras no processo pedagógico e na construção de aprendizagens nomeadas colaborativas (TORRES E IRALA, 2014).

Para a compreensão situada do trabalho pedagógico dos professores de Geografia, frente tanto as mudanças sociais globais (que interferem diretamente nos conteúdos e formas de mobilizá-los construtivamente em sala de aula) quanto a inserção de mecanismos tecnológicos contemporâneos (que incluem aparelhos, plataformas online e outros recursos similares) é preciso ponderar que a inserção das NTDIC na formação e nas práticas de ensino de Geografia viabilizam a construção de conhecimentos geográficos a partir de propostas contemporâneas que põe em relevância o ação coletiva/colaborativa, o diálogo medidado pelas redes e veículos 
de compartilhamento de informação e o protagonismo do aluno e do professor na criação de materiais que dão novas significações e condições ao processo de aprendizagem em Geografia neste século da sociedade da informação.

Partindo dessas questões, o presente trabalho objetiva apresentar reflexões e aproximações entre o método da aprendizagem colaborativa e a formação e prática docente em Geografia munidos das redes digitais, destacando desafios e possibilidades no enfrentamento de modelos de ensino, tidos como tradicionais, que estão desconexos das realidades que os alunos têm apresentado. O mesmo apoia-se em uma perspectiva crítica, que dá suporte ao aprofundamento de discussões aqui levantadas. Para tal, faz-se o levantamento de referências para compor a discussão reflexiva e propositiva acerca do tema em tela.

A adoção da aprendizagem colaborativa no ensino de Geografia é uma escolha propositiva para externar as possibilidades de um método de interação capaz de aproximar os diferentes indivíduos que compõem a escola em um processo de construção, mediação e trocas de experiências no que tange ao conhecimento de mundo.

\section{REDES DIGITAIS E APRENDIZAGEM COLABORATIVA NA CONSTRUÇÃO DE CONHECIMENTOS GEOGRÁFICOS}

As redes digitais transformaram a sociedade moderna, a percepção do tempo, do espaço e a forma como aprendemos. Além disso, possibilitaram novas formas de saber e construção de conhecimentos, visto que hoje os indivíduos têm a possibilidade de se conectar com o mundo e de maneira colaborativa construir e ressignificar conhecimentos que até pouco tempo atrás eram inviáveis.

Diante dessas evoluções, e na busca de integrar o ensino e a aprendizagem com as novas tecnologias, a aprendizagem colaborativa tem sido bastante utilizada, principalmente no estudo e desenvolvimento de novos conhecimentos científicos e no reconhecimento de saberes do senso comum, integrando alunos que não precisam estar necessariamente no mesmo espaço físico para a troca e construção de novos saberes, mas conectados a uma rede de internet que, dentre as diversas potencialidades, tem movido os usuários a um espaço navegável, negociável e carregado de informações.

A aprendizagem colaborativa, ao longo dos anos, vem sendo bastante discutida no meio acadêmico por diferentes áreas do conhecimento, pois, na sua essência, propõe a construção de aprendizagens por meio de estímulos, como ao pensamento crítico, ao desenvolvimento de 
capacidade de interação, negociação de informações e resolução de problemas (TORRES e IRALA, 2014). Esse método ajuda de forma diferenciada o aluno no processo de aprendizagem, visto que os leva a assimilar conceitos e a construir conceitos de forma autônoma. Para Gaspar (2007, p. 15), “aprendizagem colaborativa é, hoje, uma expressão de utilização frequente; ainda que corresponda a um conceito elaborado pressupõe, sempre, a existência de um grupo que interage com a finalidade de aprender". Além disso, "visará, como produto, o desenvolvimento de um projeto plural e participativo, em função do contexto social, histórico e cultural dos alunos" (p.15).

Um dos grandes propósitos deste método é a construção de conhecimento de maneira grupal, em que pares ou grupos se relacionam no intuito de solucionar problemas e compartilhar informações necessárias que beneficiem todo o conjunto. A ideia de professor como detentor e transferidor de conhecimento é extinta; ele não perde a sua autonomia na sala de aula, porém não é mais o único responsável pelo processo de aprendizagem dos alunos, mas sim pela construção de ambientes que os façam aprender. A ideia de aluno passivo e receptor de informações também é desqualificada. Em oposição à abordagem tradicional de ensino, que ainda se faz presente nas diferentes escolas do mundo, o método colaborativo reconhece o conhecimento prévio de cada estudante, sua experiência e conhecimento de mundo, ampliando e dialogando a partir por entre o coletivo.

De acordo com Torres e Irala (2014, p. 61), “o professor atua na criação de contextos e ambientes adequados para que o aluno possa desenvolver suas habilidades sociais e cognitivas de modo criativo, na interação com outrem”. E é nesses contextos que os alunos são favorecidos a construir novas formas de enxergar os objetos e se reconhecer enquanto indivíduo que pode colaborar com outros por meio das suas experiências de vida. Além disso, esses ambientes aproximam pessoas na construção de novas relações sociais.

Gaspar (2007) revela o professor como impulsionador da aprendizagem colaborativa, tendo a função de orientador que terá de cruzar com as funções de moderador, coordenador, assessor e, por vezes, de motivador. Além disso, é responsável pela preparação dos contextos para a aprendizagem, o que lhe exige uma atenção maior do processo. $\mathrm{O}$ autor reitera ainda, que "em determinados momentos do processo, o professor poderá assumir o referente de guia; mas uma das suas preocupações dominantes traduzir-se-á na necessidade de deixar espaço livre ao desempenho dos alunos" (p. 15).

Em face disto, para o ensino de Geografia, como o de qualquer ciência, quer seja humana ou natural - tendo como parâmetro as orientações curriculares para a educação básica - o 
professor assume uma postura reflexiva a todo o momento. Mas não apenas reflexiva, e sim problematizadora acerca de sua própria prática, em permanente estado de aprendizagem profissional que o habilita a perceber, analisar e intervir sobre as próprias ações, na qualidade de mediador de aprendizagens, rompendo com práticas unilaterais e ausentes do diálogo e do aprender coletivo. Significa, de acordo com Cavalcanti (2008), que os professores de Geografia, ao optar pelo colaborativismo em suas aulas, entendam a prática como objeto de reflexão-açãoreflexão, mas também que esta não está apenas associada a ele, afinal é produto de um coletivo, de um grupo-classe ali aprendendo e construindo, portanto, o desafio é maior e a complexidade dos atos também. É neste sentido que as tecnologias da informação e comunicação surgem como mecanismos que viabilizam esta forma de trabalho, criando outras estratégias e mobilizando outras formas de se relacionar com o conhecimento geográfico.

Tomando como ponto de partida tais discussões, é relevante destacar que inúmeros trabalhos publicados em revistas e periódicos demonstram que método da aprendizagem colaborativa tem contribuído significamente no processo de aprender, dispondo de características ímpares, tais como a participação, a interação e o desenvolvimento cognitivo de alunos em sala de aula e/ou no ciberespaço. Além disso, em algumas realidades, a autonomia tem sido bastante desenvolvida, tornando a colaboração em uma das possíveis maneiras de se repensar o ensino e atendendo demandas que o sistema social tem carecido.

O método colaborativo tem sido um dos caminhos adotados por professores e alunos na construção de espaços virtuais de aprendizagens. Ao analisarmos blogs, perfis de comunidades de redes sociais e sites educativos, é possível notar que uma gama de trabalhos interativos está sendo difundida nas redes, demonstrando que a aprendizagem colaborativa está presente nos diversos fazeres e pode ser viável para professores e alunos que estejam dispostos a buscar novas formas e sentidos na construção do saber popular, escolar e acadêmico.

Diante desse contexto, é válido enfatizar que a sociedade em rede (CASTELLS, 1999; 2003) proporciona um distanciamento das pessoas fisicamente, como apresentam pesquisadores, mas não têm deixado de produzir e aproximar conhecimentos que muitas vezes foram e ainda são ofuscados pela postura do professor como detentor do saber e o aluno como mero ouvinte que se apropria de informações transmitidas. A colaboração e as novas tecnologias digitais têm se apresentado como boas alternativas para a criação de novos espaços do conhecimento, do fazer imediato e, principalmente, do desenvolvimento de inúmeras habilidades do educando. 
A conexão dos dispositivos digitais acaba promovendo não só a interação dos milhares de aplicativos com as pessoas, mas também contribuído fortemente para a conexão de ideias, de linhas de raciocínio e a troca ilimitada do aprendizado. Kenski (2012) apresenta que, na atualidade, a lousa migrou para a tela (tela de computadores, tabletes, dispositivos móveis). A tela que desempenha o papel de lousa é quem desloca as atividades de ensino para experiências e vivências em novos lugares, novos grupos sociais, espaços digitais populares e colaborativos. Os espaços de aprendizagem não estão mais restritos ao perímetro da sala de aula, em que ocorre a relação fechada entre professores e alunos, mas abertos a todas as possibilidades e interações (KENSKI, 2012).

Os ambientes colaborativos apoiados por computadores são espaços virtuais, também denominados de Ambientes Virtuais de Aprendizagem-AVA, podem promover a colaboração entre alunos, distantes uns dos outros tanto no tempo como no espaço (TORRES e IRALA, 2014). A função desse espaço virtual é promover a interação e a mútua possibilidade de troca de informação, além de potencializar diferentes formas de comunicação e a construção de saberes em um processo comunicativo e relacional. Com relação ao processo de aprendizagem dentro de uma concepção mais ampla, Gaspar (2007, p. 111) salienta que:

\begin{abstract}
A aprendizagem, considerada como a substância da educação, poderá realizar-se de diferentes modos. $\mathrm{O}$ modo como se aprende está vulgarmente ligado à natureza dos resultados obtidos em relação aos objetivos enunciados e referencia-se ao significado de aprendizagem. O termo aprendizagem implica sempre ação que assume características diversas, embora tenham, em comum, a resultante na mudança, podendo, esta mudança ser considerada, apenas, no produto ou, sobretudo, no processo.
\end{abstract}

Os produtos e processos dizem respeito à condução dos alunos/aprendizes à descoberta do conhecimento. A utilização das NTDIC no processo de aprendizagem tem sofrido grandes entraves no ambiente escolar, pois muitos questionam a natureza dos conhecimentos e o modo que eles são adquiridos. A aprendizagem, na sociedade da informação e comunicação, não pode se limitar aos conteúdos programáticos, ela tem que contar com os diversos contextos dos alunos que a sala de aula apresenta. Além disso, diante das teorias da aprendizagem, dois formatos têm condicionado as relações para que o aprender aconteça: o unidirecional e multidirecional (GASPAR, 2007).

No formato unidirecional, caracteriza-se a aprendizagem individual, em que cada um desenvolve o seu caminho, traçando seu próprio objetivo e centrado no seu próprio desenvolvimento e resultados. O formato multidirecional se opõe ao que foi mencionado 
anteriormente, pois substitui o foco central do indivíduo para o grupo. Isso é percebido na aprendizagem colaborativa, pois ela tem como objetivo central os aspectos relacionais do indivíduo com o conjunto para, depois da construção do conhecimento, agir de forma interdependente nas tomadas de decisões. Almeida et al (2000), enfatizam que:

\begin{abstract}
Cada aluno, quando trabalha em grupo tenderá a articular as suas ideias com as dos colegas e organizará as suas opiniões, previsões e interpretações em função da atividade conjunta para dar a conhecer o seu pensamento. O benefício dessa articulação surge quando os alunos tentam construir um entendimento mútuo e ultrapassar os obstáculos que se opõem à construção de um conhecimento partilhado, ou seja, nos desacordos entre colegas e nos seus esforços para resolvê-los (p. 194).
\end{abstract}

No que tange o ambiente virtual, as tomadas de decisões podem ser primordiais para que a aprendizagem colaborativa aconteça, principalmente porque o virtual tem a possibilidade de agregar pessoas de diferentes personalidades em uma rede, sendo convidadas a partilharem conhecimentos. A multiplicidade de vozes na construção de um texto/produto potencializa o diálogo e a dimensionalidade que o trabalho final pode obter. Gaspar (2007) enfatiza ainda que são em contextos virtuais de aprendizagens que se constituem as comunidades de aprendizagem em que metodologicamente se desenvolve estratégias significativas para o processo de ensino e aprendizagem, configura-se como aprendizagem colaborativa.

Nessa direção, torna-se necessário destacar como as potencialidades da Web 2.0 tem contribuído significamente para a propagação do conhecimento, sendo que as redes virtuais, principalmente as sociais, têm ganhado muitas expressões na educação nos últimos anos pela potencialidade de agregar conteúdos e indivíduos em um mesmo espaço, sendo ele privado ou público, com intuito de informar, comunicar e proporcionar ambientes de interação entre o "eu e todos". Além disso, a apropriação maciça por parte dos adolescentes contribui para que a escola adote inúmeras ferramentas online no processo de ensino, motivando o aluno a ter mais interesses nos assuntos abordados.

A Web 2.0 “[...] é a segunda geração de serviços online e caracteriza-se por potencializar as formas de publicação, compartilhamento e organização de informações, além de ampliar os espaços para a interação entre os participantes do processo" (LEITE e LEÃO, 2009, p. 02). Esse conjunto de serviços online tem dado autonomia aos usuários no desenvolvimento e aprimoramento de técnicas de informática e no processo de comunicação mediado pelo computador.

Diferente da Web 1.0, em que o utilizador é apenas um consumidor da informação e possui um número limitado de ferramentas. Essas limitações tecnológicas impedem uma 
relação entre as pessoas, dificultando a troca de informações. Na Web 2.0, existe um tipo de comunicação em que o utilizador é consumidor e produtor da informação, tem maior número de ferramentas e possibilidades, facilidade de criação online e não há hierarquização do fluxo comunicacional, permitindo a relação entre as pessoas.

Um das principais vantagens da Web 2.0 na escola é a possibilidade de todos os atores do processo educativo expressarem a sua autonomia, (re)construindo histórias colaborativamente. $\mathrm{O}$ impacto das novas tecnologias na educação tem atingido proporções tão grandes que é difícil encarar o sistema de ensino desconectado com todos os emaranhados de informações que o mundo virtual apresenta, apesar de ser muito frequente. O livro, como o único recurso básico no processo de ensino e aprendizagem, já não atende mais às demandas do processo educacional vigente. Como afirmam Torres e Amaral (2011),

Torna-se cada vez mais evidente que o impacto das TIC no processo de ensino e aprendizagem depende fundamentalmente do uso pedagógico que se dá a essas tecnologias e também da forma como são adotadas nos métodos de ensino e aprendizagem e nas práticas docentes cotidianas. (p.59).

A Web 2.0 tem favorecido o surgimento de comunidades de aprendizagens virtuais que têm partilhado informações, negociação de objetivos, regularidades de comportamentos e regras, significados e identidades, entre outras características. A noção de comunidade de aprendizagem designa a união de agentes com intencionalidades específicas e que, em contextos sociais específicos, interagem e promovem a construção conjunta e a apropriação individual do conhecimento. Para o ensinar e aprender em Geografia, os desdobramentos deste mecanismo surte o efeito esperado para o que se pensa acerca de uma formação cidadã no século XXI, ou seja, centrada na globalidade dos processos, fenôemnos e relações sociais mediadas pelos fluxos em rede, possibilitados graças ao estreitamento das fronteiras físicas em decorrência da ampliação da virtualização da informação e das trocas.

Mas é preciso que se compreenda a não desqualificação da escola ou da figura do professor, em virtude de espaços de aprendizagem virtual, mas demonstrar que ambas podem ser parceiras e proporcionar aos seus alunos ambientes colaborativos de aprendizagem que independem das estruturas físicas, hierarquizadas e, muitas vezes, precarizadas da escola. A partir do momento em que os alunos são oportunizados a transformar as informações contidas na web em conhecimento, o aprendizado pode ocorrer a qualquer hora e em qualquer lugar.

Atualmente, a educação à distância online é um dos sistemas de ensino que mais tem utilizado dos produtos e processos da aprendizagem colaborativa para a produção e 
popularização de novos saberes (LEITE e LEÃO, 2009; SIQUEIRA e ALCÂNTARA, 2013). É evidente que o método colaborativo para existir independe do computador conectado à internet, mas a dimensão que as redes podem proporcionar a esse tipo de aprendizagem é de grande valia. Ou seja, é possível lidar com uma abordagem colaborativa naausência de recursos que permitam o acesso a ambientais vituais, porém estes últimos potencializam ainda mais essa maneira de construir conhecimento. Como qualquer outro tipo de proposta, a aprendizagem colaborativa online pode apresentar problemas, pois nem todas as propostas de se aprender colaborativamente são bem sucedidas. Além disso, nem todos os participantes desse processo estão dispostos a desempenhar papéis com o grupo, podendo existir ainda a falta de incentivos, mal-entendidos, conflitos e outras circunstâncias.

Embora cada indivíduo possua atitudes e pensamentos divergentes de outros, nenhum aprendiz, que participa da aprendizagem colaborativa, deve assumir a postura de líder, mas todos devem compartilhar um objetivo comum que se pretende alcançar, em que todos tenham direito de falar, discordar e juntos entrarem em consenso para a execução de alguma proposta. Essas características são encontradas tanto na educação presencial como na educação à distância.

Um ponto relevante, que não pode ser abandonado nesse tipo de aprendizagem, é a postura do professor na condução dos ambientes online para que a colaboração aconteça. É necessário que o professor tenha preparo para lidar com as diferentes situações que possam surgir, pois ele é, e sempre será, o mediador, facilitador e/ou também integrante do grupo no processo, pois ensinará e aprenderá junto com todos, visto que o foco principal da aprendizagem colaborativa não é só o conteúdo proposto, mas a troca de experiência pessoal e de vida para a transformação dos sujeitos (ALMEIDA, MIRANDA e MORAIS, 2000).

A reflexão dos aprendizes é de fundamental importância para o desenvolvimento intelectual. $\mathrm{O}$ computador conectado à internet não passa de uma simples técnica que a cada novo momento sofre mutações e aprimoramento. Esse simples artefato técnico, quando incorporado ao ensino, deve ter sentidos e contribuir para que o aluno reflita sobre as informações que estão disponíveis nos aparelhos e a importância dos mesmos na configuração da sociedade atual.

Além disso, é imprescindível reconhecer que um computador com internet não vai resolver os graves problemas que a educação básica enfrenta, porém, pode possibilitar a sociabilidade entre sujeitos e um trabalho colaborativo que desperte a autonomia quanto à aprendizagem. As redes digitais nada mais é que um novo lócus onde as relações sociais tem 
se tornado preponderantes, no sentido de despertar o interesse para a troca de conhecimentos e experiências, extrapolando as limitações físicas e as resistências de diversos professores que ainda consideram a escola como um único espaço legítimo para o ensinar e o aprender.

É preciso reconhecer que as novas tecnologias, apesar de apresentarem possibilidades e também inúmeros problemas na escola, principalmente quanto à dispersão dos alunos, elas se tornarão cada vez mais presente na sala de aula e nas mãos dos alunos, que têm adquirido sozinhas habilidades para tal manuseio (MORAN, 2000; RAMAL, 2002; OLIVEIRA, 2004; KARSENTI, 2009). A reconfiguração do ensino não está estritamente na aprendizagem colaborativa. Todavia, este pode ser um método para a transição do ensino, baseado na memorização e autoritarismo, para um modelo libertário e dialógico (FREIRE, 1996).

Este cenário de inovação tecnológica, atrelado às fortes mudanças societárias globais, que urgem por formas outras de ser-estar no mundo, e a necessidade por outra formação escolar que acompanhe este caminho, anuncia para a formação dos professores a necessidade de reconfiguração, permitindo com que estes entendem não apenas a tecnologia como um recurso didático empoeirado, tal como são os demais recursos já exaustivamente utilizados no cotidiano das escolas, mas como algo que venha a somar e a superar as fragilidades presentes no ensinaraprender Geografia na atualidade. Quer seja por meio d euma notícia acessada em um smartphone quer seja por meio de fóruns ou uso de podcasts, há maneiras diferenciadas, colaborativas e contemporâneas de elevar o ensino de Geografia a outro patamar, dando ao conhecimento geográfico na escola uma nova "cara", não mais aquela já denunciada, e ainda praticada, repetição e fixação do conteúdo. Fala-se, portanto, da construção das noções e conhecimento geográficos por intermédio dos fluxos, trocas e construções a partir dos ambientes virtuais.

De tal maneira, é preciso considerar a igual necessidade de levar aos professores clareza sobre isto, uma vez que ainda há dúvidas que pairam sobre como se materializa e se mobiliza um modo colaborativo de trabalho pedagógico em Geografia. É a partir daí que a formação profissional dos professores de Geografia deve repensar os modos como se tem conduzido as discussões e a construção da ação didática que estes profissionais do ensino devem ter frente aos desafios que a socidade da informação lhes impõe. 


\section{A FORMAÇÃO DO PROFESSOR NO CONTEXTO DOS AMBIENTES VIRTUAIS COLABORATIVOS}

Após o tratamento das contribuições do método da aprendizagem colaborativa e das redes digitais para o ensino, ambas apontadas como um caminho propositivo para a significação do processo do aprender, cabe analisar a formação do professor e a sua atuação frente ao contexto dos ambientes virtuais colaborativos que têm ganhado visibilidades no ensino básico.

Muitos professores buscam uma escola mais dinâmica, tecnológica e descentralizada e que contribua com todos os agentes que nela estão inseridos, sejam os que participam diretamente da ação educativa como os professores e alunos, sejam os coordenadores, gestores e funcionários que gerenciam processos outros, pedagógicos ou não, assim também como a comunidade de seu entorno, que (in)diretamente é influenciada pela instituição. No entanto, isso tem se tornando difícil porque a escola ainda carrega traços burocráticos, uma estrutura de funcionamento hierarquizada, organizada em especialidades e que muitas vezes não condiz com o contexto desenvolvimentista no qual está inserida (SACRISTÁN, 2000; ALARCÃO, 2001).

É muito corrente questionar até onde o professor da educação básica tem chegado para promover a aprendizagem dos seus alunos, atentando às transformações que o mundo passa. Frequentemente, críticas são lançadas às escolas quanto a ineficiência de seus processos educativas e quanto a eficiência e agilidade de dispositivos móveis, os quais têm se tornado mais atraentes que os conteúdos trabalhados ou metodologias aplicadas pelos professores. Vêse aí um ponto a pensar, como sugere Cortella (2014), afinal as mudanças provocadas pelo paradigma tecnológico-científico contemporâneo precisam também provocar mudanças na forma como as escolas, os professores, os currículos e os sistemas de ensino organizam e mobilizam os processos de construção do conhecimento e da formação escolar de base e na formação dos profissionais do ensino.

Notoriamente, mesmo com o desenvolvimento tecnológico e a apropriação massiva da população de mecanismos e ferramentas online, muitos indivíduos ainda se encontram distantes desse manuseio. Em escolas que apresentam uma série de aparatos tecnológicos, ainda existem professores que não possuem qualquer habilidade com os aparelhos ou interesse em conciliar tecnologia digital com os conteúdos ensinados, os quais poderiam apresentar novos significados para os alunos. Sabe-se que se abrir ao novo, ao desafio e a possíveis erros não é fácil, principalmente quando se tem longos anos de caminhada e um programa de trabalho já definido.

Meirinhos e Osório (2007, p. 126) argumentam que, na sociedade atual, “[...] a necessidade de formação permanente está a questionar os processos de formação e as exigências 
de quem aprende. Tornou primordial o desenvolvimento de novas competências e habilidades, passando para segundo plano a mera aquisição de informação". Atualmente, as diferentes modalidades de formação continuada (presencial e à distância-online) têm se preocupado bastante em trabalhar com as tecnologias digitais e educação, visto que as exigências para que o docente saiba lidar com essa nova tendência têm aumentado bastante.

Frente a “3” revolução industrial” (LIBÂNEO, 20011, p. 5), em que há uma pedagogigzação e intelectualização da sociedade, noemada de sociedade da informação, o papel da escola e dos professores vê-se em questão, problematizado e tratado com estranheza. É necessário que se compreenda a escola como espaço de construção de um olhar sobre esses elementos, uma vez que o excessivo contingente de informação e o elevado acesso gratuito e ágil a mecanismos de compartilhamento de experiências não garantem aprendizado efetivo dos concimento basilares a compreensão do mundo. No caso da Geografia, como disciplina escolar, há uma eminente necessidade de esta ser útil a compreensão dos processos estruturantes dessa sociedade da informação e informatizada, ao passo em que seja possível também trabalhar seus conteúdos a partir destes mecanismos tecnológicos a disposição e de amplo acesso.

O tecnológico tem atingido os mais diversos setores sociais e tem exigido das pessoas um reconhecimento desse processo de ressignificação da comunicação, entretenimento e conhecimento. "O impacto da revolução digital na formação dos professores modificou a forma como estes aprendem, como aprendem a ensinar, como interagem com os seus pares e no modo como constroem o seu conhecimento profissional" (FARIA, FARIA e RAMOS, 2013, p. 395). Para a formação de professores de Geografia, nesta perspectiva, é preciso mais que uma formação tecnológica, em que se insira a tecnologia nos percursos formativos, mas a mobilização da apropriação e do uso direito dos recursos no cotidiano escolar.

Nessa direção, para se alcançar um ensino mais interativo, que contemple a realidade dos alunos e os motive ao processo de aprender, faz-se necessário transitar de um paradigma tradicional, calcado em métodos de memorização e transcrição, para um novo paradigma emergente (CUNHA, 1998), que é nutrido por uma ação coltiva, colaborativa, investigativa, em que o professor e o aluno, por meio da colaboração, construam conhecimentos, permitindo-se navegar na descoberta do novo, sempre que necessário.

A aprendizagem colaborativa e o uso das NTDIC, na sala de aula, são instrumentos capazes de demonstrar novos significados no que tange ao conhecimento, podendo tornar os conteúdos mais atraentes e próximos aos alunos, pois, como já foi apresentado anteriormente, por meio da aprendizagem colaborativa, do mundo virtual e do coletivo, o aluno se torna um 
investigador responsável pela construção de sua aprendizagem. Além disso, o professor tem a possibilidade de aprender muito mais com os seus alunos, pois ele passa da função de conhecedor para um mediador que condiciona a criação de ambientes de trocas e descobertas. Nesse contexto, Moran (2000) salienta que:

[...] o professor precisa saber que pode romper barreiras mesmo dentro da sala de aula, criando possibilidades de encontros presencias e virtuais que levem o aluno a acessar as informações no universo da sociedade do conhecimento. [...]. O docente precisa servir-se da informática como instrumento de sua prática pedagógica, consciente de que a lógica do consumo não pode ultrapassar a lógica da produção do conhecimento. Nessa ótica, o computador e a rede devem estar a serviço da escola e da aprendizagem (MORAN, 2000, p.74).

Para que isso ocorra, muito ainda deve ser feito no processo de formação de professores, tanto na formação inicial daqueles que pretendem seguir a docência, como para aqueles que já estão atuando nas redes de ensino. Além disso, são necessários esforços por parte dos educadores no que diz respeito à sua qualificação e na sua aceitação e disponibilidade em usar a era digital ao seu favor. As Diretrizes Curriculares Nacionais da Educação Básica - DCNEB - destacam que:

[...] hoje, exige-se do professor mais do que um conjunto de habilidades cognitivas, sobretudo se ainda for considerada a lógica própria do mundo digital e das mídias em geral, o que pressupõe aprender a lidar com os nativos digitais. Além disso, lhe é exigida, como pré-requisito para o exercício da docência, a capacidade de trabalhar cooperativamente em equipe, e de compreender, interpretar e aplicar a linguagem e os instrumentos produzidos ao longo da evolução tecnológica, econômica e organizativa (BRASIL, 2013, p. 61).

Os desafios impostos aos professores não abarcam somente mudar os eixos do ensinar pelos caminhos que levem a aprenderl, ele necessita atualizar os seus conhecimentos científicos e buscar espaços para a reflexão sobre o fazer pedagógico por meio de leituras, pesquisas específicas e troca de experiências para que possa desenvolver habilidades para trabalhar em equipe. Como é salientado por Gianotto e Diniz (2010, p.632), “[...] o bom desempenho do exercício da profissão de professor exige, além de saberes teóricos (conteúdos), conhecimentos, habilidades, competências e saberes específicos da docência”.

É necessário expor, embasado nas constatações de educadores (ZEICHNER, 1993; LIBÂNEO, 2000; MIZUKAMI, 2002), que o tipo de formação que os professores estão submetidos nos últimos tempos não contribui para que o aluno se desenvolva como pessoa autônoma, que possa agir e tomar decisões como cidadão em um mundo cada vez mais exigente 
e informatizado. Daí a necessidade da formação de novos professores e despertá-los para racionalidades reflexivas, que compreendam o seu papel na sociedade, formando indivíduos que saibam se organizar socialmente e que experimentem as mudanças no mundo contemporâneo. Gianotto e Diniz (2010) acreditam que:

\begin{abstract}
A melhoria da qualidade de ensino passa, necessariamente, pela revisão dos padrões de formação de professores, pois a maioria dos cursos de licenciatura têm seus currículos apoiados na concepção de professor como um profissional que deverá aplicar conhecimentos adquiridos em situações específicas e, portanto, não forma o professor capaz de ensinar o aluno a pensar (p. 634).
\end{abstract}

A interação, o ensinar a pensar criticamente, o impacto da NTDIC no âmbito escolar, e outras características comunais, deve ser ingrediente comum na formação inicial dos professores, pois isso fortalece a ideia de que o professor deve deixar de ser apenas o repassador de conhecimento (o computador pode exercer esse papel), e passar a ser o criador de situações de aprendizagem e mediador do desenvolvimento cognitivo do aluno (FREIRE, 1996). Ou seja, significa tornar o professor um agente de conhecimento, a partir de um processo dinâmico e reflexivo voltado a problematização e resolução de situações que estimulem os alunos a pensar, propor e executar ações, não apenas a ouvir e consentir.

$\mathrm{O}$ uso adequado das ferramentas digitais pode auxiliar no processo de ensino e aprendizagem, porém, os bons resultados dessa mediação só são alcançados quando os alunos trocam conhecimento entre si acerca do que aprenderam, enxergando a tecnologia apenas como um meio e não como a única alternativa de se obter o conhecimento que foi adquirido, principalmente porque as ferramentas utilizadas são meros recursos didáticos, pois o aprendizado depende unicamente do aprendiz que é submetido à experiência pedagógica. Dessa forma, Moran (2000, p. 75) destaca que:

\footnotetext{
Os alunos passam a ser descobridores, transformadores e produtores do conhecimento. A qualidade e a relevância da produção dependem também dos talentos individuais dos alunos que passam a ser considerados como portadores de inteligências múltiplas. Inteligências que vão além das linguísticas e do raciocínio matemático que a escola vem oferecer. Como parceiros, professores e alunos desencadeiam um processo de aprendizagem cooperativa para buscar a produção do conhecimento.
}

Desafiados por elementos visuais, sonoros e textuais virtuais, os professores são levados a conhecer novos tipos de linguagem e signos que são bastante utilizados na comunicação entre os alunos. Faz-se necessário, em muitos casos, uma alfabetização digital para entender esse tipo de linguagem, mas ele não encontrará isso no curso de formação inicial 
e/ou continuada, devido às fortes mutações que o digital e suas particularidades apresentam. Todavia, os próprios alunos podem contribuir para que professores aprendam essas novas linguagens, possibilitando que os mesmos tenham maiores facilidades com manuseio de ferramentas digitais, se comuniquem com outros professores e busquem, dentro do contexto digital da colaboração, mecanismos para avaliação dos trabalhos desenvolvidos.

Qualquer proposta de intervenção de ação pedagógica, exercida pelo professor, requer uma reflexão profunda sobre a sua atuação, visto que as práticas exercidas devem apresentar elementos significativos para o aluno. O planejamento das aulas e as estratégias decorrentes devem levar em consideração os anseios dos indivíduos submetidos ao processo do aprender e de que forma eles poderão elaborar o conhecimento que os permitam ganhos.

Como Vygotsky (1984) salienta, a aprendizagem não é fruto apenas da interação do indivíduo com o meio e não ocorre de maneira isolada; o processo de ensino e aprendizagem envolve diferentes agentes, como aqueles que aprendem e ensinam e aqueles que ensinam e aprendem (a troca mútua entre aluno-professor-aluno). Moura (2007) chama esse processo de ensinagem centrada nos grupos. Na aprendizagem colaborativa munida pelas redes digitais, essa relação de aprender e ensinar são indissociáveis, pois colaborativamente não existem hierarquias para a construção do conhecimento; os envolvidos nesse método compartilham experiências, ensinam e aprendem juntos. Tais aspectos têm a possibilidade de contribuir diretamente para a construção sócio-crítica dos envolvidos, abarcando conhecimentos formais e informais.

Com relação à metodologia de ensinagem centrada nos grupos, Moura (2009) enfatiza que ela envolve os procedimentos de ensinagem selecionados. É coordenado e apoiado pelo professor, mas desenvolvido por um grupo de alunos, cujo objetivo é permitir que os mesmos, de forma coletiva, pesquisem, descubram e exponham experiências dos conhecimentos obtidos em grupo. A autora também destaca que, através das trocas entre os alunos e intervenção do professor, novas aprendizagens podem ser apropriadas.

Contudo, a prática do professor deve estar alicerçada nos princípios que colaboram para a construção conjunta de signos e significados na sala de aula, permitindo que as habilidades dos aprendizes sejam valorizadas. "Ampla é a missão do docente, que não pode prescindir em oferecer uma oportunidade de aprendizagem para o aluno que está pronto para dela fazer uso e construir novos conhecimentos" (SIQUEIRA e ALCÂNTARA, 2003, p. 2).

Sendo assim, professores de Geografia conscientes do seu papel na sala de aula e qualificados, buscando nas dificuldades da escola e especificidades dos alunos novas caminhos 
para a construção de ambientes favoráveis para o ensino participativo e lúdico, têm sim a possibilidade de formar indivíduos dotados de uma consciência crítica e sociopolítica a respeito da sociedade mundo. Não esquecendo também da igual necessidade da existência de parcerias entre instituições de formação inicial, gestões públicas e escolares, pais e os próprios estudantes como potencializadores para ressignificação do sistema de ensino.

Portanto, diante das constatações e indagações, é possível reconhecer que estamos longe de responder todas as questões no que tange ao processo ensino e aprendizagem, seja em Geografia ou qualquer outro campo do saber. Ter respostas para todas as questões poderia ser também uma maneira equivocada de enxergar a educação, visto que ela não é estática e possui uma multiplicidade de realidades e renovações. Além disso, trilhamos por inúmeros desafios que ora se convergem como possibilidades, ora se opõem, revelando a necessidade de criarmos novas rotas para entender toda complexidade que a sociedade atual tem apresentado. Nas escolas, a todo o momento somos postos à prova e desafiados por uma nova geração de alunos que já nascem tecnologicamente conectados. O atual período, denominado técnico-científicoinformacional (SANTOS, 1994), tem oportunizado uma maior apropriação dos aparelhos técnicos digitais e fortalecido a ideia de sociedade conectada.

Buscar mecanismos de ação para entender e lidar com essas realidades é de fundamental importância; a escola não deve ficar à margem do desenvolvimento que a sociedade tem desencadeado, principalmente porque dela são cobrados vários esforços para formação de indivíduos que saibam reagir frente às contemporâneas mudanças sociais e socioestruturais. A necessidade de formar indivíduos ativos, que pensem criticamente o seu lugar no mundo, acaba recaindo sobre o professor, que deve se abrir ao novo para contribuir no direcionamento desses alunos.

A sociedade muda e cobra da escola mudanças, principalmente porque ela ainda preserva traços antigos de dominação e poder (PACHECO, 2005). Novos espaços julgados como informais têm favorecido que conhecimentos do senso comum e científicos sejam construídos, popularizados e se confluam. As paredes físicas da escola passam a dar lugar aos novos espaços invisíveis, os ciberespaços dotados de funcionalidades e com abertura para o mundo. A mudança desse cenário não está estritamente na escola ou no professor, pois sabemos que, por trás dos mesmos, existem inúmeros agentes, mas é por meio da instituição e dos profissionais que a compõem que podemos começar o processo de mudança social, olhando a sala de aula para além de um espaço burocratizado, como um ambiente de trocas, de relações sociais e de formação de sujeitos críticos-reflexivos. 


\section{APONTAMENTOS INCONCLUSIVOS}

Postos estes apontamentos teórico-metodológico e inconclusivas discussões, é preciso reconhecer que a temática aqui tratada está longe de se esgotar, até porque o seu esgotamento está condicionado a uma mudança positiva no ensino e na aprendizagem ou em uma reconfiguração do modelo de escola e de formação de professores. Assim, na atual configuração educacional, tida ainda como hierarquizada e burocratizada, é impossível cessar com as reflexões que atravessam as questões aqui tratadas.

É primordial reconhecer que a escola tem que ser um ambiente de tensões, de aportes críticos e principalmente de possibilidade à mudança social. Compreender o ensino e o professor como um arcabouço enciclopédico, atualmente, é questionar a função da escola. $\mathrm{O}$ professor é um agente importante na transformação do ensino, mesmo reconhecendo que o aluno é a centralidade do ato de ensinar. Não podemos reprimir ou recusar o professor como proponente deste processo, até porque, na aprendizagem colaborativa, além de mediador e oportunizador dos ambientes de ensino, o educador é um integrante do processo que também aprende com os seus educandos.

Se tratando da aprendizagem colaborativa, diversas concepções e olhares devem ser dados a esse método no intuito de reconhecer o ensino escolar como transformador de indivíduos que transformam a sociedade. Todavia, para que os alunos cumpram esse papel, são necessários professores capacitados, que vejam no ensino novas possibilidades de abertura para a democratização do saber, além de estarem abertos ao diálogo, às perguntas e às curiosidades dos alunos, bem como suas inibições e desejos, reconhecendo que ensinar não é transferir conhecimento, mas uma troca de experiências em processo de dialogicidade.

Nesse contexto de produção de conhecimento, diálogo e sociabilidade, as redes digitais têm sido um novo aprimoramento técnico, capaz de desestabilizar as estruturas físicas e hierárquicas quanto à produção de novas aprendizagens. A conexão tem fortalecido os laços sociais, além de ter contribuído para que a visibilidade das informações e produções chegue a lugares distintos em um fluxo imediato.

Portanto, formar professores, para que executem um trabalho contextualizado com as diversas realidades e teoricamente mais crítico-reflexivo, é cada vez mais urgente, visto que a sociedade, tida como tecnológica, tem marginalizado os indivíduos que não se apropriam das tecnologias digitais a favor de suas atividades. Esse panorama não pode ocorrer com a 
educação, pois ela é a base para a construção da cidadania nos indivíduos, além de estimular a intelectualidade, habilidades, entre outros.

Numa mirada ao ensinar-aprender Geografia e formar professores para atuarem neste processo, é nítida, como proposto nesta discussão, a vasta contribuição que a adoção da aprendizagem colaborativa pode possibilitar à construção do conhecimento geográfico na escola do tempo presente, numa sociedade da informação. Rever os roteiros pedagógicos escolares e acadêmicos, onde de um lado está o professor a atuar e de outro está o futuro professor a se tornar um profissional do ensino de Geografia, é necessário e importante, uma vez que os professores de Geografia de hoje precisam estar prontos para lidar com alunos que chegam às escolas cheios de informações e que precisam ser orientados por estes para organizarem todo esse conjunto de questões para que consigam enxergar a socidade como ela funciona e como eles conseguem se enxergar e atuar nela.

\section{REFERÊNCIAS}

ALARCÃO, I. A escola reflexiva. In: ALARCÃO, I. (org). Escola reflexiva e nova racionalidade. Porto Alegre: Artmed Editora, 2001.

ALENCAR, G. A.; MOURA, M. R.; BITENCOURT, R. B. Facebook como plataforma de ensino/aprendizagem: o que dizem os professores e alunos do IFSertão - PE. Educação, Formação \& Tecnologias. 6 (1), 86-93, Jul. 2013.

ALMEIDA, C. DIAS, P. MORAIS, C. MIRANDA, L. Aprendizagem Colaborativa em Ambientes Baseados na Web. In: BARCA, A. e PERALBO, M. (Eds), V Congresso GalegoPortugués de Psicopedagoxia. Actas - No 4, V. 6, 2000.

BRASIL. Diretrizes Curriculares Nacionais da Educação Básica. Brasília: Ministério da Educação, Secretaria de Educação Básica, 2013.

CASTELLS, M. A galáxia da internet: reflexões sobre a internet, os negócios e a sociedade; tradução Maria Luiza X de A. Borges, Rio de Janeiro: Jorge Zahar, 2003.

. A Sociedade em Rede. 2. ed. São Paulo, Paz e Terra, 1999.

CORTELLA, M. S. Educação, escola e docência: novos tempos, novas atitudes. São Paulo: Cortez, 2014

CUNHA, M. I. O professor universitário na transição de paradigmas. Araraquara: JM editora, 1998. 
FARIA, A.; FARIA, P. M.; RAMOS, M. A. Formação e desenvolvimento profissional docente em rede: entre o presencial e o online. Educação em Perspectiva, Viçosa, v. 4, n. 2, p. 393417, jul./dez. 2013.

FREIRE, P. Pedagogia da autonomia: saberes necessários à prática educativa. 13. ed. Rio de Janeiro: Paz e Terra, 1996.

GASPAR, M. I. Aprendizagem colaborativa online. In: AIRES, L.; AZEVEDO, J.; GASPAR, M. I.; TEIXEIRA, A. (org). Comunidades Virtuais de Aprendizagem e Identidades no Ensino Superior. Lisboa: Universidade Aberta, 2007.

GIANOTTO, D. E. P.; DINIZ, R. E. S. Formação inicial de professores de biologia: a metodologia colaborativa mediada pelo computador e a aprendizagem para a docência. Ciência \& Educação, v. 16, n. 3, p. 631-648, 2010.

KARSENTI, Thierry. Impacto das TIC (Tecnologias de Informação e Comunicação) sobre a atitude, a motivação, a mudança nas práticas pedagógicas dos futuros professores. In: TARDIF, M.; KENSKI, V. M. Educação e tecnologias: o novo ritmo da informação. 3. ed. Campinas, SP: Papirus, 2007.

KENSKI, V. M. Tecnologias e ensino presencial e a distância. $9^{\text {a }}$ ed. Campinas, SP: Papirus, 2012.

LEITE, B. S.; LEÃO, M. B. C. A Web 2.0 como ferramenta de aprendizagem no ensino de Ciências. XIV TALLER INTERNACIONAL DE SOFTWARE EDUCATIVO, 2009, Santiago.

LIBÂNEO, J. C. Adeus professor, adeus professora?: novas exigências educacionais e profissão docente. 4. ed. São Paulo: Cortez, 2000.

153-176, 2001.

Pedagogia e pedagogos: inquietações e buscas. Educar, Curitiba, n. 17, p.

MEIRINHOS, M; OSÓRIO, A. Factores condicionantes da aprendizagem colaborativa em ambientes virtuais: estudo de caso no âmbito da formação contínua de professores. In: AIRES, L.; AZEVEDO, J.; GASPAR, M. I.; TEIXEIRA, A. (org). Comunidades Virtuais de Aprendizagem e Identidades no Ensino Superior. Lisboa: Universidade Aberta, 2007.

MIZUKAMI, M. G. N.; REALI, A. M. M. R. Formação de professores, práticas pedagógicas e escola. São Carlos: EdUSFSCar, 2002.

MORAN, J. M. Novas Tecnologias e mediação pedagógica. Campinas, SP: Papirus, 2000.

MOURA, T. M. M. Metodologia do Ensino Superior: saberes e fazeres da/para a prática docente. $2^{\mathrm{a}}$. ed. Maceió: EDUFAL, 2007.

OLIVEIRA, Maria Auxiliadora Monteiro (org.). Novas linguagens e novas tecnologias: Educação e sociabilidade. Petrópolis: Vozes, 2004. 
OSTROVSKI, C. S.; RAITZ, T. R. Tecnologias e formação para o trabalho docente na sociedade contemporânea. Revista Educação e Cultura Contemporânea, v. 13, n. 31, p. 181201, 2016.

PRETTO, N. L. O desafio de educar na era digital: educações. Revista Portuguesa de Educação, no 24(1), p. 95-118, 2011.

RAMAL, Andréa Cecília. Educação na Cibercultura - Hipertextualidade, Leitura, Escrita e Aprendizagem. Porto Alegre: Artmed, 2002.

SANTAELLA, L. Da cultura das mídias à cibercultura: o advento do pós humano. Revista FAMECOS, Porto Alegre, $n^{\circ}$ 22, p. 23-32, dez. 2003.

SIQUEIRA, L. M. M.; ALCÂNTARA, P. R. Modificando a atuação docente utilizando a colaboração. Revista Diálogo Educacional, Curitiba, v. 4, n.8, p.57-69, jan./abr. 2003.

TORRES, P. L.; ALCANTARA, P; R.; ILARA, E. A. F. Grupos de consenso: uma proposta de aprendizagem colaborativa para o processo de ensino-aprendizagem. Revista Diálogo Educacional, Curitiba, v. 4, n.13, p. 129-145, set./dez. 2004.

TORRES, P. L.; IRALA, E. A. F. Aprendizagem Colaborativa: Teoria e Prática. In: TORRES, P. L. (Org.). Complexidade: Redes e Conexões na Produção do Conhecimento. $1^{\text {a }}$ ed.Curitiba: SENARPR, v. 1, p. 61-93, 2014.

TORRES, T. Z.; AMARAL, S. F. Aprendizagem Colaborativa e Web 2.0: proposta de modelo de organização de conteúdos interativos. Educação Temática Digital, Campinas, v.12, n.esp., p.49-72, mar. 2011.

VYGOTSKY, L. S. A formação social da mente: o desenvolvimento dos processos psicológicos superiores. 1. ed. São Paulo: Martins Fontes, 1984.

ZEICHNER, K. M. A formação reflexiva de professores: ideias e práticas. Lisboa: Educar, 1993. 